\title{
Corpus callosum agenesis-intellectual disability-coloboma-micrognathia syndrome
}

INSERM

\section{Source}

INSERM. (1999). Orphanet: an online rare disease and orphan drug data base. CorpuS callosum agenesis-intellectual disability-coloboma-micrognathia syndrome. ORPHA:52055

Corpus callosum agenesis-intellectual disability-coloboma-micrognathia syndrome is a developmental anomalies syndrome characterized by coloboma of the iris and optic nerve, facial dysmorphism (high forehead, microretrog nathia, low-set ears), intellectual deficit, agenesis of the corpus callosum (ACC), sensorineural hearing loss, skeletal anomalies and short stature. 